Supplement of Hydrol. Earth Syst. Sci., 22, 3143-3154, 2018

https://doi.org/10.5194/hess-22-3143-2018-supplement

(C) Author(s) 2018. This work is distributed under

the Creative Commons Attribution 4.0 License.

(c) (1)

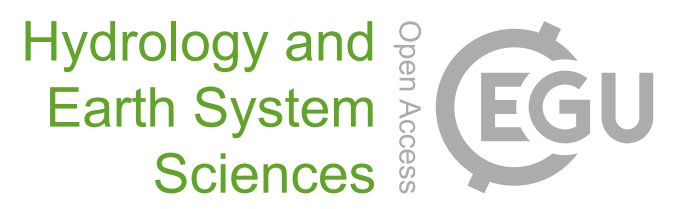

Supplement of

\title{
Recent trends of groundwater temperatures in Austria
}

\section{S. A. Benz et al.}

Correspondence to: Susanne A. Benz (susanne.benz@kit.edu)

The copyright of individual parts of the supplement might differ from the CC BY 4.0 License. 

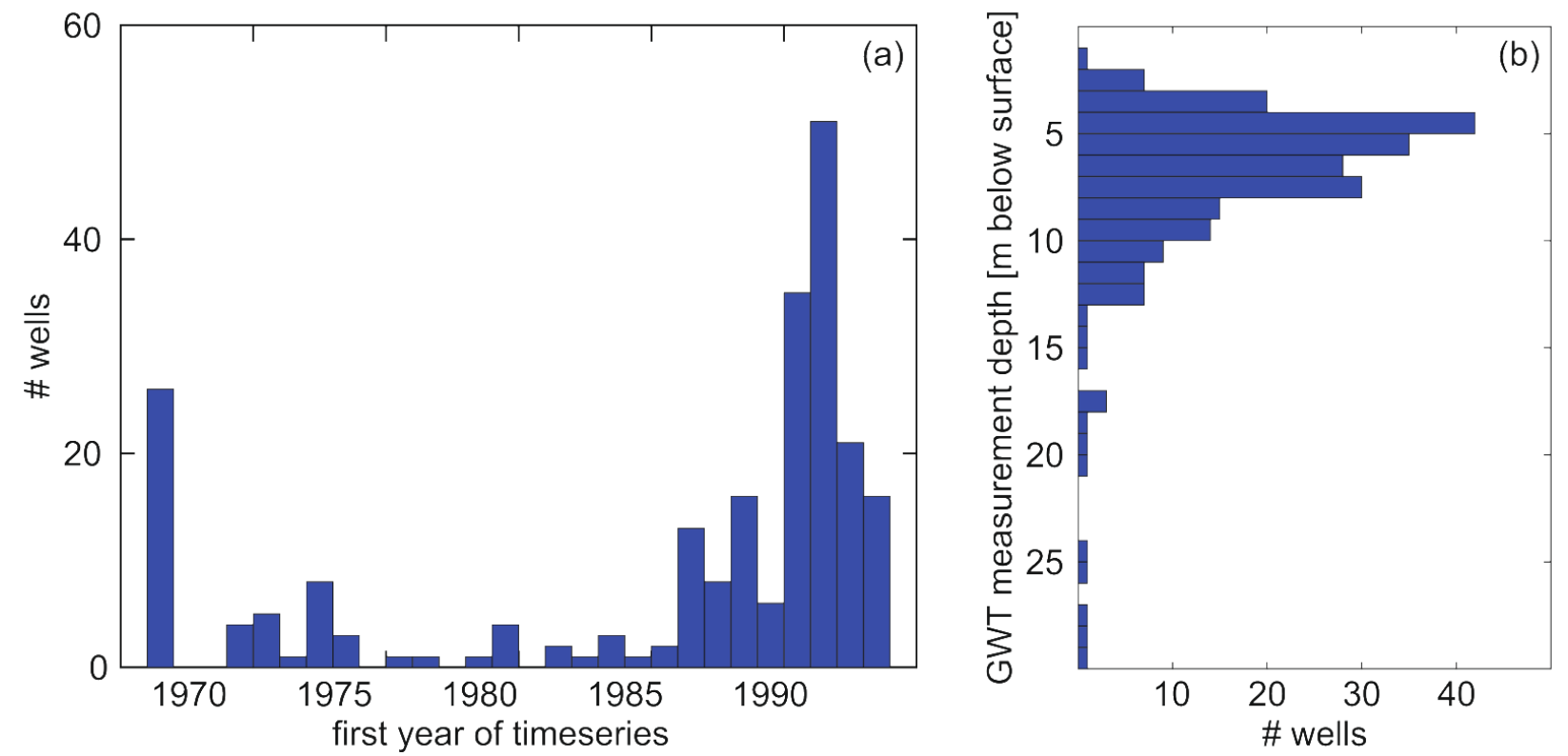

Figure S1. a) Histogram showing the starting year of each GWT time series. All analyzed time series end in December 2013 and are at least 20 years long. b) Histogram showing the GWT measurement depth of each well. The mean depth is $7 \pm 4 \mathrm{~m}$ below ground. 

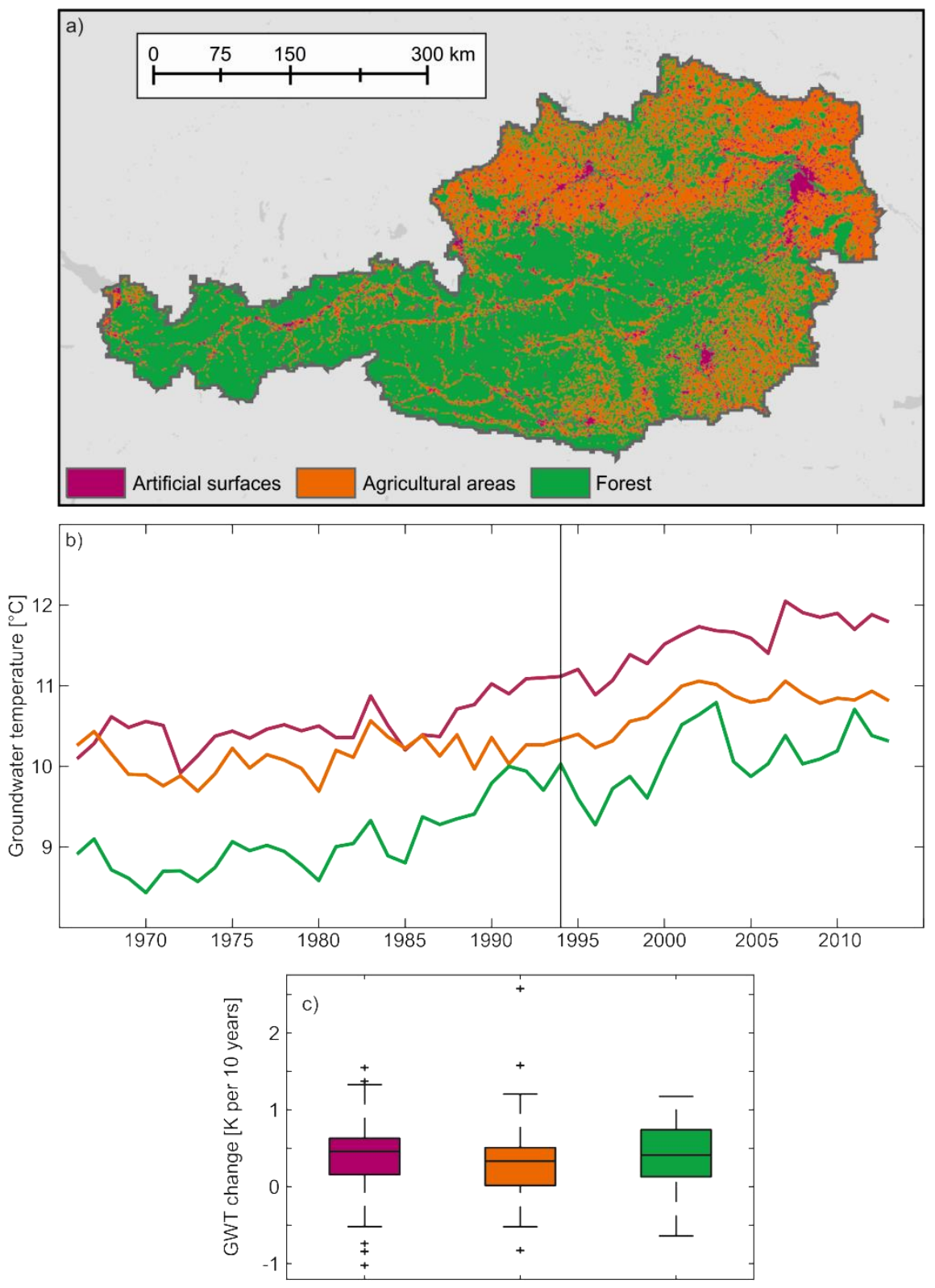

Figure S2. a) Corine Land Cover 2012 of Austria. None of the analyzed wells and weather stations experienced a land cover change since 1990. b) Spatial median GWTs for each of the individual land cover classes. All wells are monitored since at least 1994. c) Relationship between land cover and groundwater temperature (GWT) change between 1994 and 2013. There appears to be no significant influence. 

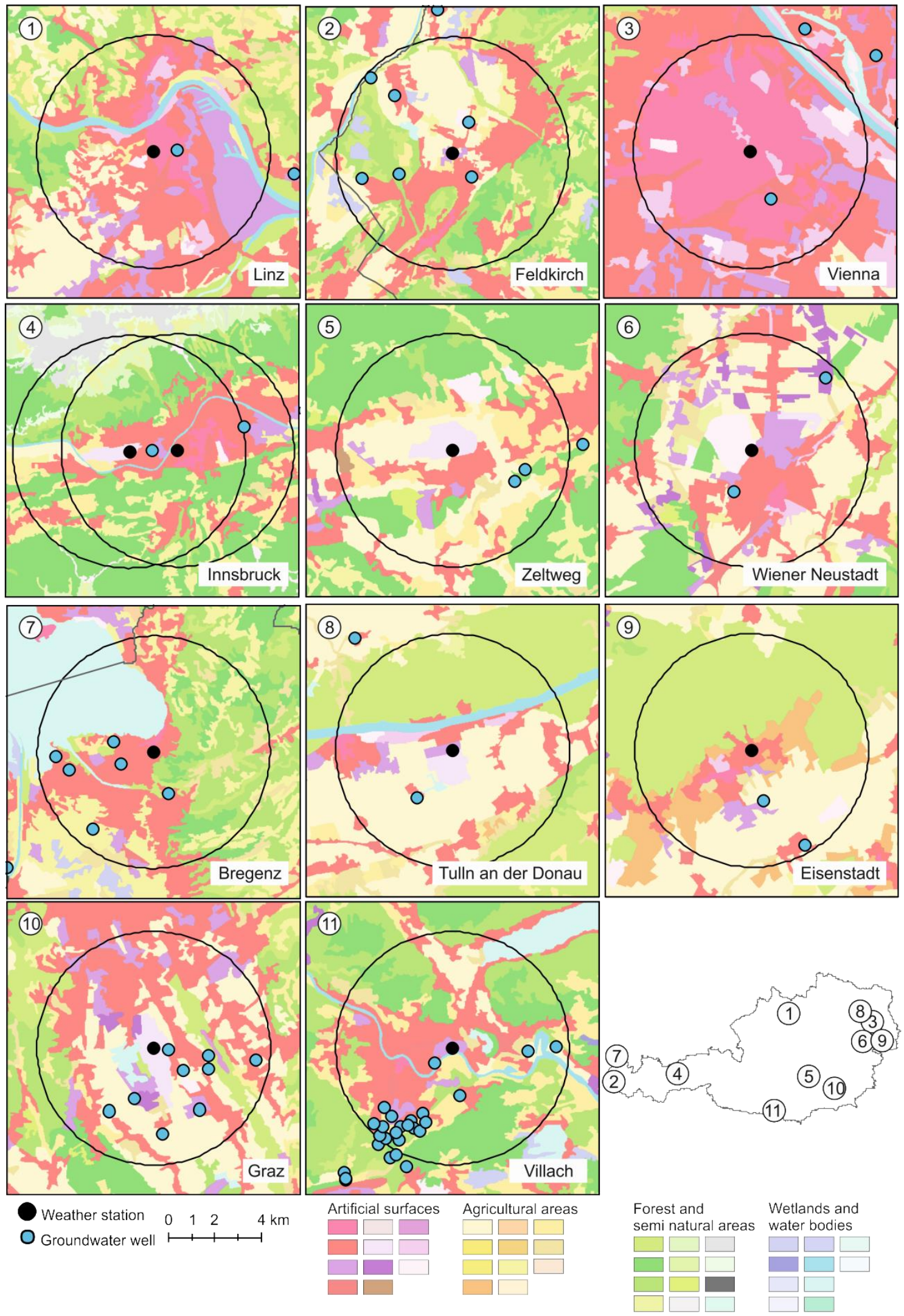

Figure S3: Location of all analysed weather stations and the surrounding wells. In the last part of this study all wells within $5 \mathrm{~km}$ (black circle) of any weather station are analysed. 

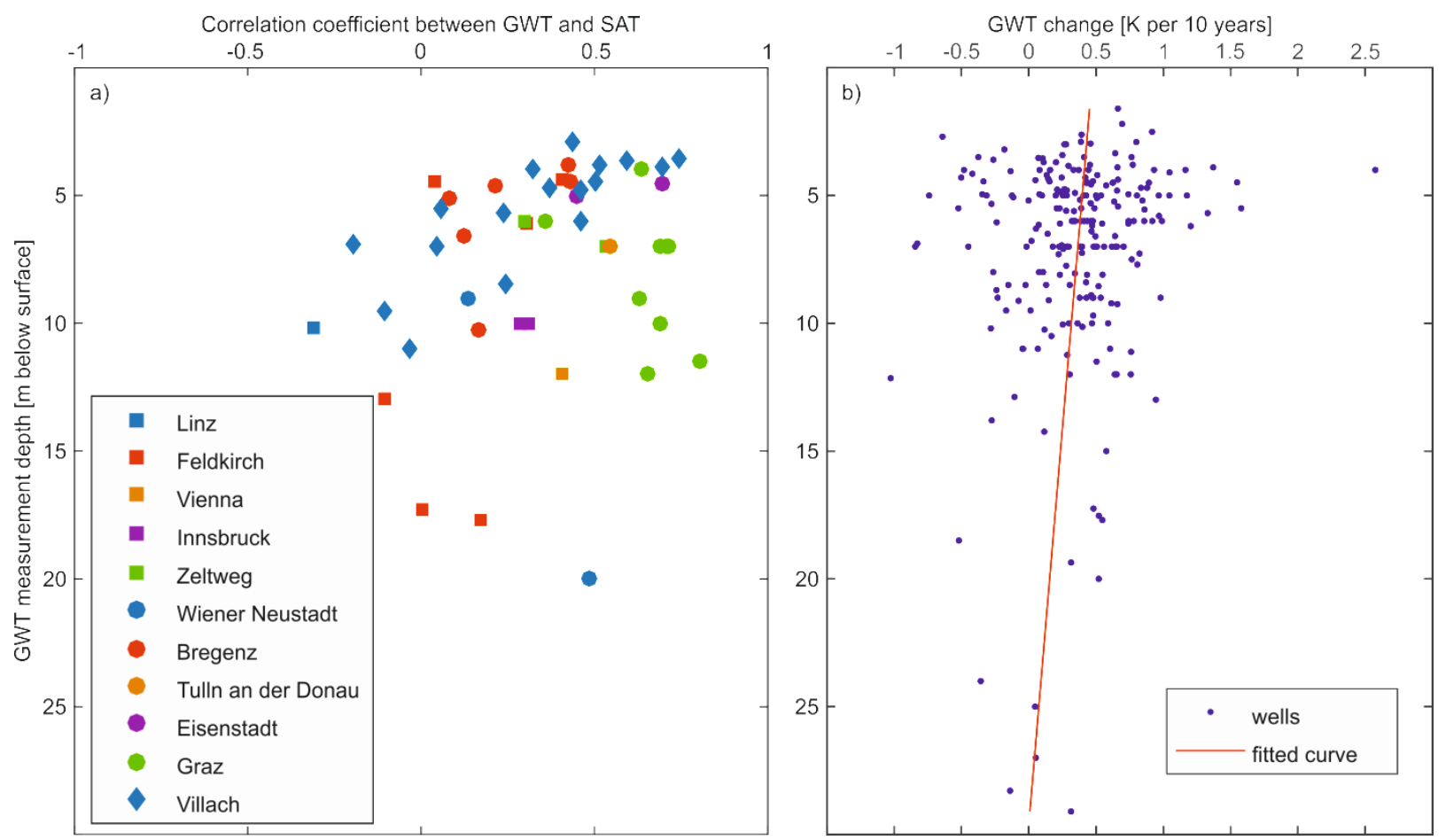

Figure S4: a) Influence of measurement depth on Spearman correlation between GWT and nearby SAT measurements. Shown are results for all wells depicted in Fig. S3. b) Influence of measurement depth on observed change in temperature. The best fit implies a linear temperature change of $0.48 \mathrm{~K}$ per 10 years for a depth of $0 \mathrm{~m}$ and a decrease in temperature change by $0.015 \mathrm{~K}$ per 10 years for each additional meter between measurement point and surface. 


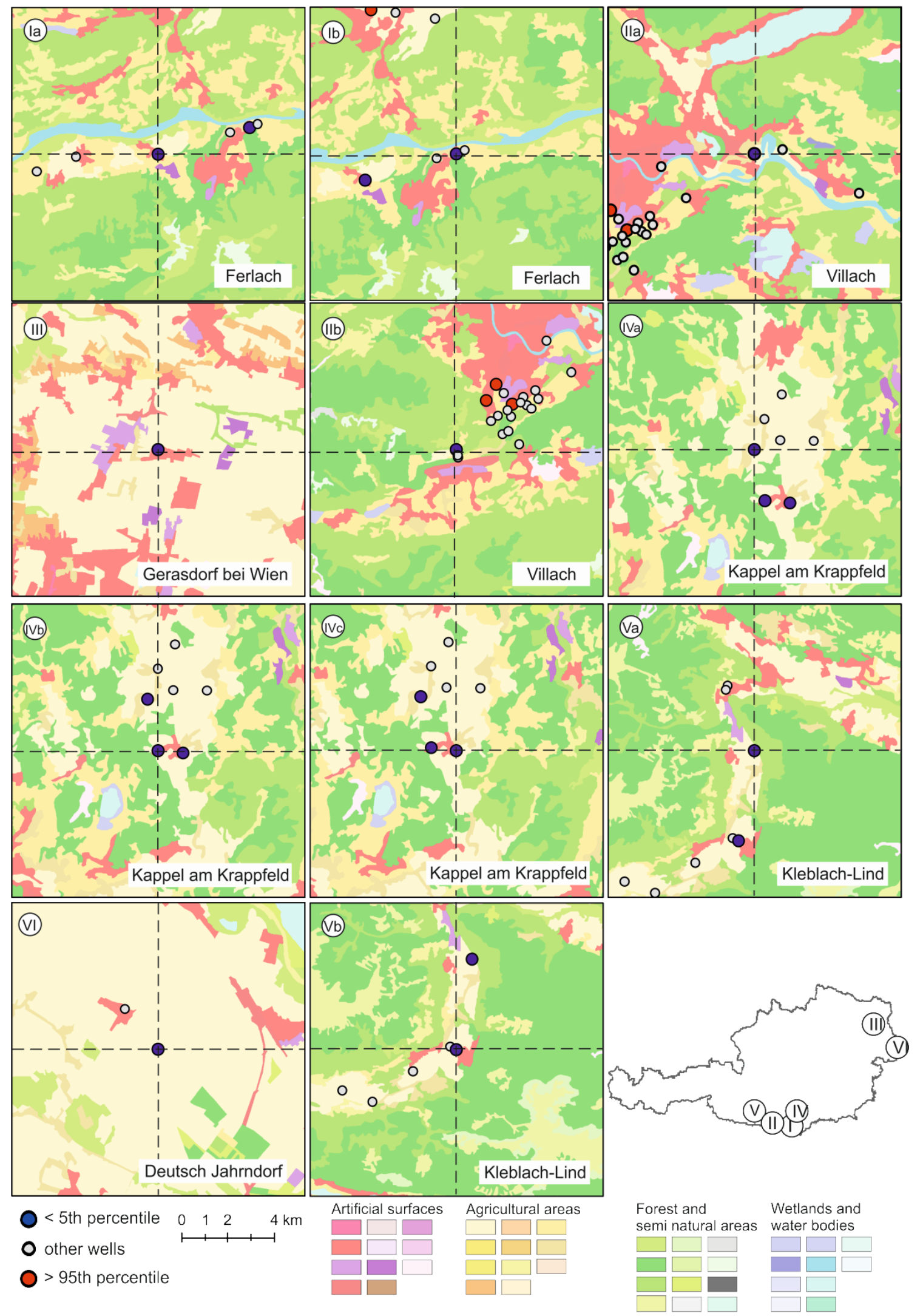

Figure S5. Location of all wells with a temperature change $<5^{\text {th }}$ percentile. 


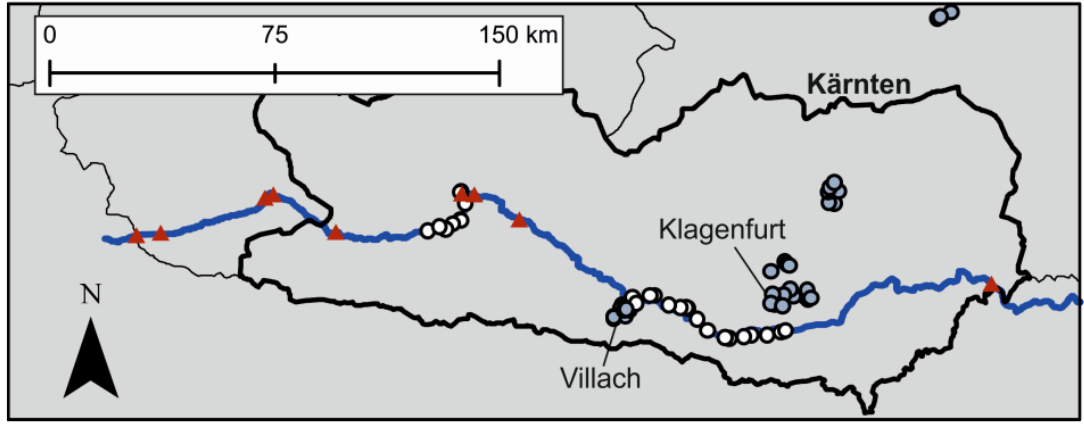

$\begin{array}{llll}\text { Drava river } & 0 & \text { well }>1 \mathrm{~km} \text { from Drava river } \\ \Delta \quad \text { measurement station in Drava } & \circ & \text { well }<1 \mathrm{~km} \text { from Drava river }\end{array}$

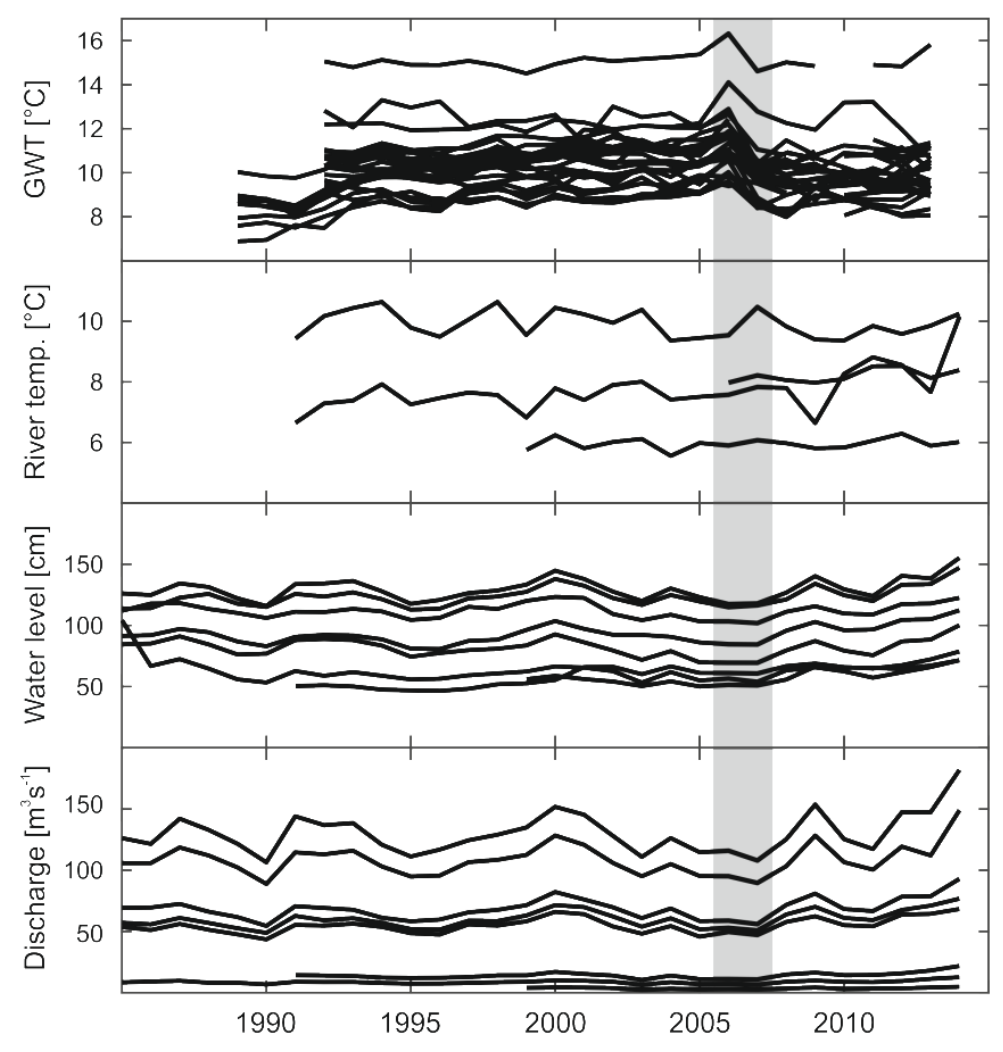

Figure S6. Location of the Drava river, the groundwater monitoring wells around it and measurement stations within the river (BMNT). Also shown is the groundwater time series of all wells within $1 \mathrm{~km}$ of the river and all measured river parameters. While GWTs show a sudden drop in 2007 (marked in red), observed river parameters give no indication of an abnormal event around that time. 


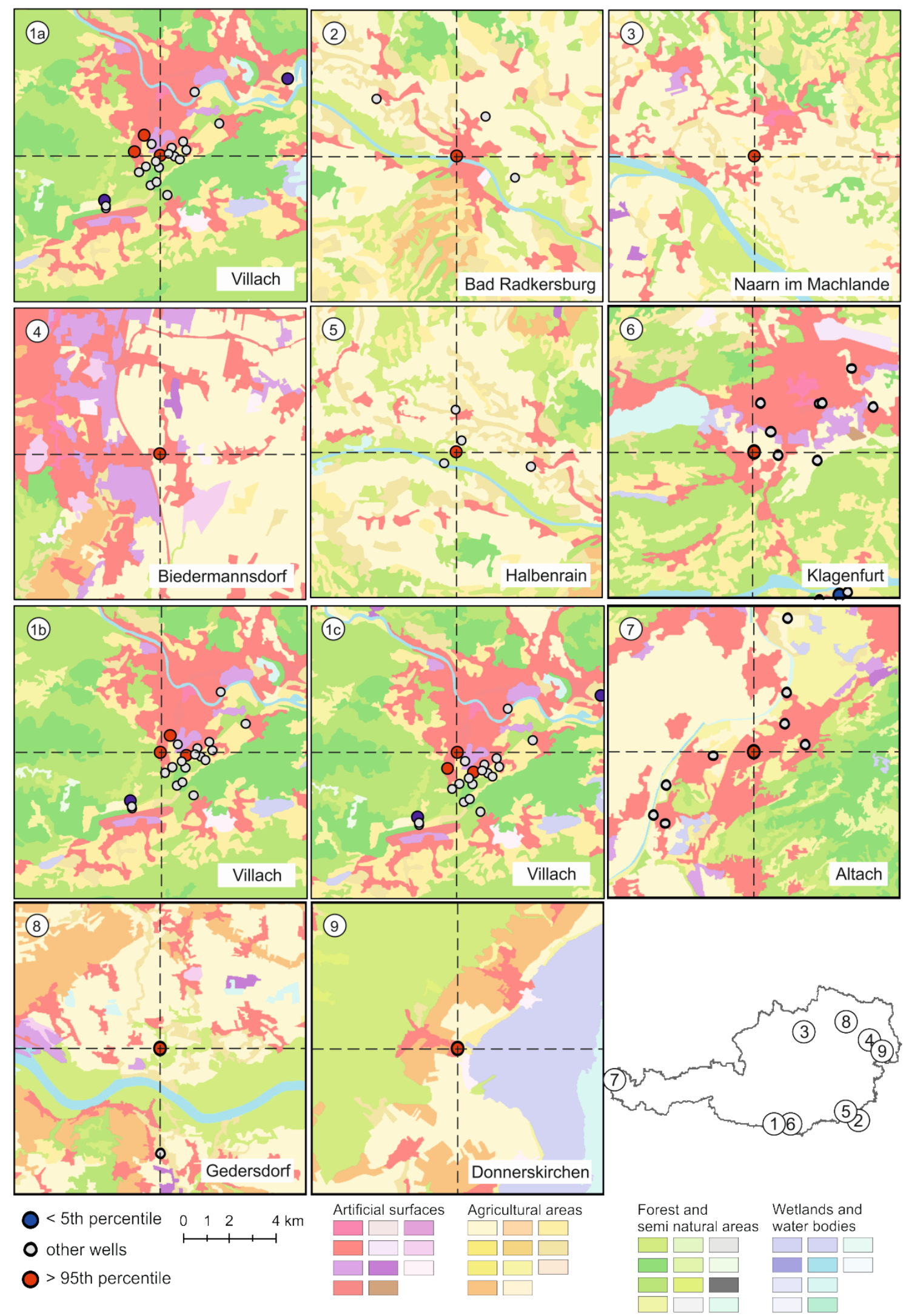

Figure S7. Location of all wells with a temperature change $>95^{\text {th }}$ percentile. 


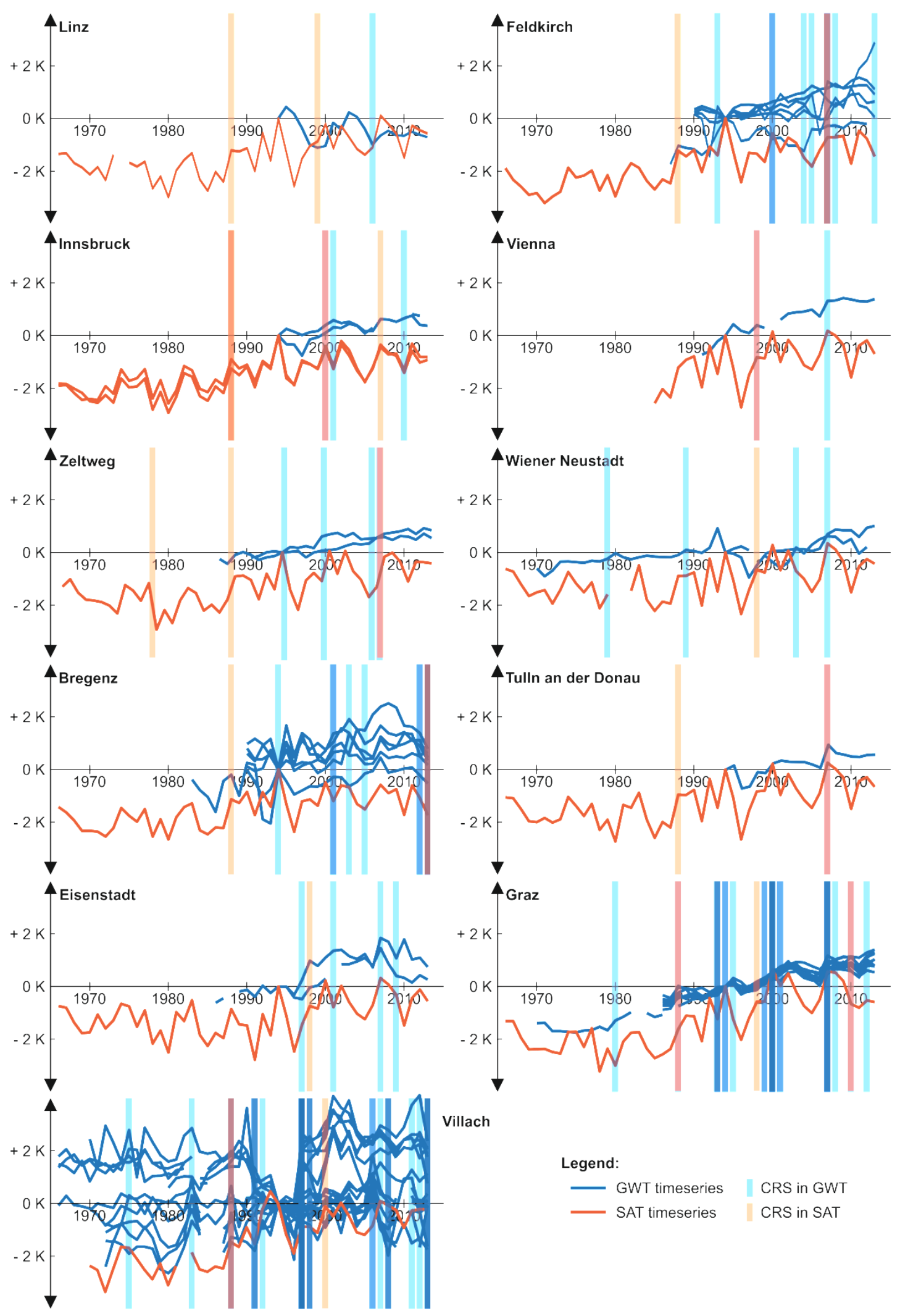

Figure S8. Climate regime shifts (CRS) of wells and weather stations within $5 \mathrm{~km}$ of each other. Darker colors indicate more measurements stations with CRSs. 


\section{References}

BMNT: Austrian Federal Ministry of Sustainability and Tourism Directorate-General IV. - Water Management, eHYD, http://ehyd.gv.at/, access: 12.10.2017. 